\title{
COMPORTAMENTO PÓS-COLHEITA DAS CARACTERÍSTICAS QUÍMICAS, BIOQUÍMICAS E FÍSICAS DE FRUTOS DE TOMATEIROS HETEROZIGOTOS NOS LOCOS ALCOBAÇA E RIPENING INHIBITOR
}

\author{
ALCIDES MILITÃO DOS SANTOS JUNIOR ${ }^{1}$ \\ WILSON ROBERTO MALUF ${ }^{2}$ \\ MARCOS VENTURA FARIA ${ }^{3}$ \\ LUIZ CARLOS DE OLIVEIRA LIMA ${ }^{4}$ \\ KARINA PEREIRA DE CAMPOS ${ }^{5}$ \\ HERBERT CAVALCANTE DE LIMA ${ }^{6}$ \\ FRANCISCA MARTA M. C. DE ARAÚJO ${ }^{6}$
}

\begin{abstract}
RESUMO - Os alelos mutantes alc e rin retardam o processo de amadurecimento do tomate (Lycopersicon esculentum Mill.), interferindo principalmente na síntese de pigmentos carotenóides e na firmeza dos frutos. Com este trabalho, objetivou-se avaliar e comparar os efeitos dos alelos mutantes alc e rin, em heterozigose $\left(\right.$ alc ${ }^{+} /$alc e $\left.\mathrm{rin}^{+} / \mathrm{rin}\right)$ sobre características químicas, bioquímicas e físicas de frutos de tomateiro em três estádios de maturação. Os alelos alc e rin em heterozigose não exerceram influência marcante sobre o teor de sólidos solúveis totais dos frutos nos estádios de maturação apropriados para o consumo. O genótipo $\mathrm{rin}^{+} / \mathrm{rin}$ atuou mais intensamente no sentido de reduzir os teores de
\end{abstract}

licopeno e, conseqüentemente, promover maior deficiência na coloração vermelha dos frutos quando comparado ao efeito do genótipo alc ${ }^{+} / a l c$. Nos frutos maduros, a atividade da enzima pectinametilesterase sofreu maior redução pela ação do genótipo $\mathrm{rin}^{+} / \mathrm{rin}$. O genótipo alc ${ }^{+} / a l c$ foi mais eficiente em reduzir a atividade da poligalacturonase. No estádio breaker, não houve influência dos alelos em heterozigose sobre os teores de celulose, hemicelulose e pectina dos frutos. No estádio intermediário, o genótipo $\mathrm{rin}^{+} /$rin promoveu redução na fração hemicelulose. No estádio maduro, o alelo rin em heterozigose promoveu redução significativa nos teores de celulose e pectina do material da parede celular.

TERMOS PARA INDEXAÇÃO: Tomate, mutantes de amadurecimento, conservação pós-colheita, Lycopersicon esculentum.

\section{POST-HARVEST BEHAVIOUR OF CHEMICAL, BIOCHEMICAL AND PHYSICAL ASPECTS OF TOMATO FRUITS HETEROZYGOUS IN ALCOBACA AND RIPENING INHIBITOR LOCI}

\begin{abstract}
The ripening mutants alc and rin delay tomato (Lycopersicon esculentum Mill.) ripening and affect synthesis of carotenoids pigments and fruit firmness. This paper reports on the comparative effects of heterozygous alc and rin genotipes $\left(a l c^{+} /\right.$alc and $\mathrm{rin}^{+} / \mathrm{rin}$ ) on chemical, biochemical and physical aspects
\end{abstract}

of tomato fruit during three ripening stages. Neither alc/alc nor $\mathrm{rin}^{+} / \mathrm{rin}$ influenced total solids contents in the intermediary or fully ripe stages. The genotype $\mathrm{rin}^{+} /$rin brought about a more marked reduction in lycopene than alc ${ }^{+} / a l c$, relative to the normal genotype. In mature fruit, pectinmethylesterase activity was more

1. Doutorando em Agronomia/Fitotecnia - UNIVERSIDADE FEDERAL DE LAVRAS/UFLA, Caixa Postal 37 37.200-000 - Lavras, MG.

2. PhD., Professor Titular do Departamento de Agricultura/UFLA. wrmaluf@ufla.br

3. Doutorando em Agronomia - DBI/UFLA.

4. Professor do Departamento de Ciência dos Alimentos/UFLA.

5. Mestrando em Agronomia - DAG/UFLA.

6. Doutorando - DCA/UFLA. 
markedly by $\mathrm{rin}^{+} / \mathrm{rin}$, whereas alc $^{+} /$alc was more effective in reducing polygalacturose activity. In the breaker stage, neither mutant affected cellulose, hemicellulose or pectin contents. In the intermediary stage hemicellulose was reduced by $\mathrm{rin}^{+} /$rin and, in mature stage, $\mathrm{rin}^{+} / \mathrm{rin}$ reduced cell wall cellulose and pectin fractions. Both alc $/$ alc and $\mathrm{rin}^{+} / \mathrm{rin}$ can be efficiently deployed in breeding long shelf life tomato hybrids.

INDEX TERMS: Tomato, ripening mutants, post harvest shelf life, Lycopersicon esculentum.

\section{INTRODUÇÃO}

O tomate (Lycopersicon esculentum Mill) é classificado como fruto climatérico e está entre os produtos agrícolas recordistas em perdas, em razão da sua elevada perecibilidade. O complexo processo de maturação dos frutos é controlado geneticamente e coordenado por uma série de alterações fisiológicas e bioquímicas que afetam principalmente o sabor, odor, cor e textura (Lurie et al., 1996), que tornam o fruto aceitável para o consumo. $\mathrm{O}$ amadurecimento caracteriza-se por uma seqüência de alterações sincronizadas e evidenciadas por mudanças na taxa respiratória, produção de etileno, síntese de carotenóides, desenvolvimento de "flavor", alteração na textura (Lobo, 1981), degradação da clorofila, produção de açúcares, alteração no metabolismo de ácidos orgânicos e amidos, aumento na atividade de enzimas pectolíticas, maturação das sementes (Tigchelaar et al., 1978), que ocorrem em um período relativamente curto.

Algumas pesquisas visam a melhorar as características químicas, tais como, sólidos solúveis totais (SST), acidez total titulável (ATT) e $\mathrm{pH}$ dos frutos. As variações no teor de sólidos solúveis totais entre os frutos de diferentes genótipos são atribuídas a diversos fatores, entre os quais a capacidade do fruto de importar assimilados fotossintéticos. Aproximadamente metade da matéria seca dos tomates é constituída por açúcares redutores, cerca de $25 \%$ ácidos orgânicos e aminoácidos, lipídeos e minerais e o restante, sólidos insolúveis em álcool. Desse modo, avalia-se a importância dos açucares e ácidos orgânicos como constituintes principais tanto da matéria seca total como dos sólidos solúveis totais em tomates (Young et al., 1993).

A aparência do fruto, baseada principalmente na coloração, é um atributo de qualidade que afeta diretamente a sua aceitação comercial (Gómez et al., 1998). A coloração externa do tomate é resultado da pigmentação da polpa e da casca e a cor é condicionada não só pela quantidade total de carotenóides, mas também pela relação licopeno/betacaroteno, a qual é importante na coloração final, variando com o grau de maturação. Os genes alc e rin interferem diretamente na síntese de pigmentos carotenóides (Lobo, 1981). Em homozigose, esses mutantes afetam drasticamente a síntese de licopeno (Kopeliovitch et al., 1979; Lobo, 1981) e betacaroteno (Araújo, 1997), não permitindo que os frutos desenvolvam coloração aceitável; entretanto, em heterozigose (alc ${ }^{+} /$alc $\mathrm{e}$ $\mathrm{rin}^{+} /$rin), atuam no sentido de prolongar a firmeza sem que a coloração se torne um fator limitante.

A redução da textura é resultado da atividade de enzimas hidrolíticas de parede celular que interferem na integridade dos tecidos sob ação da pectinametilesterase (PME) e poligalacturonase (PG) (Vilas Boas, 1998). Os alelos mutantes alc e rin, situados em locos distintos no genoma do tomateiro, inibem o processo natural de maturação dos frutos, interferindo principalmente na firmeza devido à redução da atividade de enzimas hidrolíticas de parede celular, desacelerando o processo de amolecimento dos frutos (Filgueiras, 1996). O nível e a atividade dessas enzimas podem ser reduzidos mesmo quando esses mutantes estão em heterozigose $\left(\right.$ alc $c^{+} /$alc ou $\mathrm{rin}^{+} / \mathrm{rin}$ ), proporcionando frutos com melhor textura, embora essa resposta seja em função do background genético (Araújo, 1997).

Objetivou-se com a execução deste trabalho quantificar e comparar os efeitos relativos dos alelos mutantes alc e rin, em heterozigose (alc ${ }^{+} / a l c$ e $\mathrm{rin}^{+} / \mathrm{rin}$ ), em genótipos híbridos quase isogênicos de tomateiro sobre características químicas, bioquímicas e físicas dos frutos de tomateiro em três estádios de maturação.

\section{MATERIAL E MÉTODOS}

O experimento foi instalado e conduzido na Estação de Pesquisa da HortiAgro Sementes Ltda, no município de Ijaci-MG, e no laboratório de Fisiologia PósColheita do Departamento de Ciência dos Alimentos da Universidade Federal de Lavras, no ano de 2001. O germoplasma utilizado faz parte do programa de melhoramento genético do tomateiro da HortiAgro Sementes Ltda.

Foram avaliados frutos de 4 híbridos de tomateiro longa-vida, sendo um o híbrido comercial Carmen $\mathrm{F}_{1}$, heterozigoto para o loco $\mathrm{rin}\left(\mathrm{alc}^{+} / \mathrm{alc}^{+}, \mathrm{rin}^{+} / \mathrm{rin}\right) \mathrm{e}$ três híbridos experimentais quase isogênicos com 
background híbrido (Floradade $\mathrm{x}$ Tropic) que diferem entre si nos locos rin e alc: (1) $\mathrm{F}_{1}$ (Floradade $\mathrm{x}$ Tropic), normal nos locos alc e rin $\left(\right.$ alc $^{+} /$alc $^{+}$, rin $^{+} /$rin $\left.^{+}\right)$; (2) $\mathrm{F}_{1}$ (TOM-610 x Floradade), heterozigoto para o loco alc $\left(\right.$ alc ${ }^{+} /$alc, rin $^{+} /$rin $\left.^{+}\right)$e (3) $\mathrm{F}_{1}$ (TOM-619 x Floradade), heterozigoto para o loco $\mathrm{rin}\left(\mathrm{alc}^{+} / \mathrm{alc}^{+}, \mathrm{rin}^{+} / \mathrm{rin}\right)$. O experimento foi conduzido em delineamento inteiramente casualizado, com duas repetições, em esquema fatorial 4 x 3, correspondendo aos 4 genótipos e 3 estádios de maturação [breaker (início de manchas de coloração vermelha na região da cicatriz estilar), intermediário (40 a $60 \%$ da área da superfície com coloração vermelha) e maduro (acima de $80 \%$ da área da superfície com coloração vermelha)]. As unidades experimentais foram constituídas por amostras compostas de cinco frutos, colhidos em cada um dos 3 estádios de maturação.

\section{Características avaliadas}

Sólidos solúveis totais: determinados com refratômetro digital ATAGO PR-1000 e expressos em graus brix, segundo AOAC (1992);

Acidez total titulável: realizada por titulação, filtrado com $\mathrm{NaOH}$ 0,1M, segundo Instituto Adolfo Lutz (1985);

$\boldsymbol{p H}$ : determinado por potenciometria, em potenciômetro Digimed modelo DMpH-2. (1963);

Clorofila total: determinada conforme Bruinsma

Pigmentos carotenóides (licopeno e betacaroteno): determinados conforme Nagata \& Yamashita (1992).

Textura dos frutos: determinada com penetrômetro Mc-Cormick com ponta de 7,94 mm de diâmetro. As medidas foram realizadas após remoção do pericarpo da região equatorial, em três pontos em cada fruto, evitando-se as paredes radiais internas. As leituras expressas em N.m ${ }^{-2}$.

Enzimas poligalacturonase e pectinametilesterase: foram quantificadas utilizando-se a metodologia de Goren \& Mosnseline (1969), citados por Araújo (1997) e expressas em unidades por grama de peso fresco.

O material da parede celular dos frutos foi extraído do tecido mesocárpico como descrito por Mitcham \& McDonald (1992), com poucas modificações e, a partir daí, foram avaliadas as seguintes características:

Celulose e hemicelulose: a concentração de açúcares neutros nessas frações foi determinada pelo método de antrona, segundo Dische (1962), sendo os resultados expressos em porcentagem na parede celular;

Pectina: O teor de ácidos urônicos foi dosado pelo método do carbazol (Bitter \& Muir, 1962) e os resultados, expressos em porcentagem de pectina no material da parede celular.

Contrastes entre os três híbridos quase isogênicos definirão os efeitos das constituições genotípicas alc $^{+} /$alc, $\mathrm{rin}^{+} / \mathrm{rin}$ relativamente ao genótipo normal para as características avaliadas. $\mathrm{O}$ contraste entre a testemunha comercial Carmen $\mathrm{F}_{1}\left(\mathrm{alc}^{+} / \mathrm{alc}^{+} \mathrm{rin}^{+} / \mathrm{rin}\right)$ e os demais tratamentos quantificará o comportamento desses últimos relativamente ao primeiro. $\mathrm{O}$ contraste entre Carmen $\mathrm{F}_{1}$ e o híbrido experimental de genótipo $\mathrm{rin}^{+} /$rin definirá o efeito dos diferentes backgrounds genéticos numa mesma constituição genotípica no loco $\operatorname{rin}\left(\operatorname{rin}^{+} / \mathrm{rin}\right)$

\section{RESULTADOS E DISCUSSÃO}

Os teores de sólidos solúveis totais (SST) dos frutos dos híbridos heterozigotos nos locos alc ou rin não foram alterados significativamente quando comparados com os frutos do híbrido isogênico normal, independentemente do estádio de maturação (Tabela 1). No estádio intermediário, para acidez total titulável (ATT), as estimativas dos contrastes (Híbrido experimental normal vs Híbrido experimental $a l c^{+} / a l c$ ) e (Híbrido experimental normal vs Híbrido experimental $\mathrm{rin}^{+} / \mathrm{rin}$ ) foram positivas e significativas (Tabela 1 ), inferindo-se que mutantes alc e rin em heterozigose promoveram redução na acidez titulável total (ATT) dos frutos em relação ao genótipo normal.

Entretanto, não se observaram diferenças para os mesmos contrastes quando os frutos encontraramse nos estádios breaker e maduro. No estádio maduro, o contraste [Carmen $\mathrm{F}_{1}\left(\mathrm{rin}^{+} / \mathrm{rin}\right)$ vs Híbrido experimental $\mathrm{rin}^{+} / \mathrm{rin}$ ] para a porcentagem de ATT foi positivo e significativo, indicando um possível efeito do background genético sobre essa característica (Tabela 1). As estimativas do contraste (Híbrido experimental alc $c^{+} / a l c$ vs Híbrido experimental $\mathrm{rin}^{+} /$rin) para a variável $\mathrm{pH}$ foram negativas e significativas tanto no estádio breaker quanto no estádio intermediário de maturação, demonstrando que o loco $a l c^{+} /$alc promoveu redução do $\mathrm{pH}$ dos frutos, quando comparado com o loco $\mathrm{rin}^{+} /$rin. Entretanto, o pH não foi afetado por esses dois locos no estádio maduro. 
TABELA 1 - Contrastes não-ortogonais e sua estimativas para sólidos solúveis total (SST), acidez total titulável (ATT) e pH de frutos de 4 genótipos de tomateiro em função dos alelos mutantes rin e alc. e do estádio de maturação. Lavras-MG: UFLA, 2001.

\begin{tabular}{|c|c|c|c|c|}
\hline \multirow[b]{2}{*}{ Contrastes de interesse } & \multirow{2}{*}{$\begin{array}{c}\text { Estádio } \\
\text { de maturação }\end{array}$} & \multicolumn{3}{|c|}{ Estimativas dos contrastes } \\
\hline & & $\begin{array}{c}\text { SST } \\
\left({ }^{\circ} \text { brix }\right)\end{array}$ & $\begin{array}{l}\text { ATT } \\
(\%)\end{array}$ & pH \\
\hline Carmen $\mathrm{F}_{1}$ vs Híbrido experimental normal & breaker & $1.2^{*}$ & $-0.035^{\mathrm{ns}}$ & $0.10^{\mathrm{ns}}$ \\
\hline Carmen $\mathrm{F}_{1}$ vs Híbrido experimental $a l c^{+} / a l c$ & breaker & $1.2^{*}$ & $-0.025^{\mathrm{ns}}$ & $0.25^{* *}$ \\
\hline Carmen $\mathrm{F}_{1}$ vs Híbrido experimental $\mathrm{rin}^{+} /$rin & breaker & $1.2^{*}$ & $-0.035^{\mathrm{ns}}$ & $0.00^{\mathrm{ns}}$ \\
\hline Híbrido experimental normal vs Híbrido exp. $a l c^{+} / a l c$ & breaker & $0.0^{\mathrm{ns}}$ & $0.010^{\mathrm{ns}}$ & $0.15^{*}$ \\
\hline Híbrido experimental normal vs Híbrido exp. $\mathrm{rin}^{+} / \mathrm{rin}$ & breaker & $0.0^{\mathrm{ns}}$ & $0.000^{\mathrm{ns}}$ & $-0.10^{\mathrm{ns}}$ \\
\hline Híbrido experimental alc ${ }^{+} / a$ lc vs Híbrido exp. $\mathrm{rin}^{+} / \mathrm{rin}$ & breaker & $0.0^{\mathrm{ns}}$ & $0.010^{\mathrm{ns}}$ & $-0.25^{* *}$ \\
\hline Carmen $\mathrm{F}_{1}$ vs Híbrido experimental normal & intermediário & $0.0^{\mathrm{ns}}$ & $-0.130^{* *}$ & $0.05^{\text {ns }}$ \\
\hline Carmen $\mathrm{F}_{1}$ vs Híbrido experimental alc $/ a l c$ & intermediário & $0.4^{\mathrm{ns}}$ & $-0.025^{\mathrm{ns}}$ & $0.05^{\mathrm{ns}}$ \\
\hline Carmen $\mathrm{F}_{1}$ vs Híbrido experimental $\mathrm{rin}^{+} / \mathrm{rin}$ & intermediário & $0.4^{\mathrm{ns}}$ & $-0.030^{\mathrm{ns}}$ & $-0.10^{\mathrm{ns}}$ \\
\hline Híbrido experimental normal vs Híbrido exp. alc $/ a l c$ & intermediário & $0.4^{\mathrm{ns}}$ & $0.105^{* *}$ & $0.00^{\mathrm{ns}}$ \\
\hline Híbrido experimental normal vs Híbrido exp. $\mathrm{rin}^{+} / \mathrm{rin}$ & intermediário & $0.4^{\mathrm{ns}}$ & $0.100^{* *}$ & $-0.15^{*}$ \\
\hline Híbrido experimental alc ${ }^{+} / a l c$ vs Híbrido exp. $\mathrm{rin}^{+} / \mathrm{rin}$ & intermediário & $0.0^{\mathrm{ns}}$ & $-0.005^{\mathrm{ns}}$ & $-0.15^{*}$ \\
\hline Carmen $\mathrm{F}_{1}$ vs Híbrido experimental normal & maduro & $-0.2^{\mathrm{ns}}$ & $-0.095^{* *}$ & $-0.05^{\mathrm{ns}}$ \\
\hline Carmen $\mathrm{F}_{1}$ vs Híbrido experimental alc $/$ alc & maduro & $-0.4^{\mathrm{ns}}$ & $-0.085^{*}$ & $0.00^{\mathrm{ns}}$ \\
\hline Carmen $\mathrm{F}_{1}$ vs Híbrido experimental rin $^{+} /$rin & maduro & $0.2^{\text {ns }}$ & $0.075^{*}$ & $-0.10^{\mathrm{ns}}$ \\
\hline Híbrido experimental normal vs Híbrido exp. alc ${ }^{+} / a l c$ & maduro & $-0.2^{\mathrm{ns}}$ & $0.010^{\mathrm{ns}}$ & $-0.05^{\mathrm{ns}}$ \\
\hline Híbrido experimental normal vs Híbrido exp. $\mathrm{rin}^{+} / \mathrm{rin}$ & maduro & $0.4^{\mathrm{ns}}$ & $0.020^{\mathrm{ns}}$ & $-0.05^{\mathrm{ns}}$ \\
\hline Híbrido experimental alc ${ }^{+} / a$ lc vs Híbrido exp. $\mathrm{rin}^{+} / \mathrm{rin}$ & maduro & $0.6^{\mathrm{ns}}$ & $0.010^{\mathrm{ns}}$ & $-0.10^{\mathrm{ns}}$ \\
\hline
\end{tabular}

**, Significativo ao nível de $1 \%$ e $5 \%$, respectivamente, pelo $\mathrm{F}$.

$\mathrm{O}$ alelo mutante alc em heterozigose promoveu redução significativa nos teores de licopeno e betacaroteno em frutos maduros (Tabela 2), conforme acusou a estimativa do contraste (Híbrido experimental normal vs Híbrido experimental alc $\left.{ }^{+} / a l c\right)$. Já o mutante rin, em heterozigose, promoveu redução no teor de licopeno dos frutos, nos três estádios de maturação avaliados. As estimativas do contraste (Híbrido experimental alc $/$ alc vs Híbrido experimental $\mathrm{rin}^{+} / \mathrm{rin}$ ) foram positivas e significativas nos três estádios de maturação avaliados (Tabela 2), demonstrando que o genótipo $\mathrm{rin}^{+} /$rin apre- sentou efeito mais drástico sobre a redução da síntese de licopeno nos frutos quando comparado ao efeito do genótipo alc $/$ alc; no entanto, o teor de betacaroteno nos frutos maduros $\mathrm{rin}^{+} / \mathrm{rin}$ foi significativamente superior ao teor encontrado nos frutos alc ${ }^{+} /$alc.

$\mathrm{O}$ contraste [Carmen $\mathrm{F}_{1}\left(\mathrm{rin}^{+} /\right.$rin) vs Híbrido experimental $\mathrm{rin}^{+} / \mathrm{rin}$ ] (Tabela 2), nos três estádios de maturação avaliados, apresentou estimativas positivas e significativas para o teor de licopeno, significando que o background genético do híbrido Carmen $\mathrm{F}_{1}$ é favorável para obtenção de frutos com maior teor de licopeno 
e, conseqüentemente, com coloração vermelha mais intensa quando maduros em relação ao background do híbrido experimental (Floradade x Tropic). Da mesma forma, nos estádios intermediário e maduro, o teor de betacaroteno foi favorecido pelo background do híbrido Carmen $\mathrm{F}_{1}$. As diferenças no teor de betacaroteno entre frutos maduros alc ${ }^{+} /$alc e rin $^{+} /$rin são inferiores, no entanto, as que podem ser obtidas pela modificação do background genotípico, conforme demonstra o contraste 'Carmen $\mathrm{F}_{1}$ vs híbridos experimentais $\mathrm{rin}^{+} / \mathrm{rin}$ ' (Tabela 2).

Quanto aos teores de clorofila, nos estádios intermediário e maduro, o alelo alc em heterozigose promoveu redução mais rápida do teor de clorofila dos frutos (Tabela 2).
Os pigmentos licopeno, betacaroteno e clorofila foram influenciados pelo estádio de maturação dos frutos. À medida que os frutos atingiram estádios mais avançados de maturação, o teor de clorofila foi reduzido, ao passo que os teores de licopeno e betacaroteno sofreram aumento. Os frutos maduros provenientes dos híbridos experimentais normais $\left(\mathrm{alc}^{+} / \mathrm{alc}^{+}, \mathrm{rin}^{+} / \mathrm{rin}^{+}\right)$apresentaram teores de licopeno e betacaroteno mais elevados, quando comparados com frutos oriundos dos híbridos experimentais quase isogênicos heterozigotos para o loco alc ou rin, confirmando o efeito desses mutantes na redução de pigmentos carotenóides. O loco $\mathrm{rin}^{+} / \mathrm{rin}$ atuou mais intensamente no sentido de reduzir os teores de carotenóides e, conseqüentemente, promoveu maior deficiência na coloração vermelha dos frutos, quando comparado ao efeito do loco alc ${ }^{+} /$alc.

TABELA 2 - Contrastes não-ortogonais e suas estimativas para teores de licopeno, betacaroteno e clorofila de frutos de híbridos de tomate longa-vida em função dos alelos mutantes rin e alc e diferentes estádios de maturação. Lavras-MG: UFLA, 2001.

\begin{tabular}{|c|c|c|c|c|}
\hline \multirow[b]{2}{*}{ Contrastes de Interesse } & \multirow[b]{2}{*}{$\begin{array}{c}\text { Estádio } \\
\text { de maturação }\end{array}$} & \multicolumn{3}{|c|}{ Estimativas } \\
\hline & & $\begin{array}{l}\text { Licopeno } \\
\text { (mg/100g) }\end{array}$ & $\begin{array}{c}\text { Betacaroteno } \\
\text { (ig/100g ) }\end{array}$ & $\begin{array}{l}\text { Clorofila } \\
(\mathrm{mg} / \mathbf{1 0 0 g})\end{array}$ \\
\hline Carmen $\mathrm{F}_{1}$ vs Híbrido experimental normal & breaker & $-0,0003^{\mathrm{ns}}$ & $-11,000^{* *}$ & $0,285^{*}$ \\
\hline Carmen $\mathrm{F}_{1}$ vs Híbrido experimental alc ${ }^{+} / a l c$ & breaker & $-0,0039^{* *}$ & $-6,235^{* *}$ & $0,175^{*}$ \\
\hline Carmen $\mathrm{F}_{1}$ vs Híbrido experimental $\mathrm{rin}^{+} /$rin & breaker & $0,0036^{* *}$ & $-25,085^{* *}$ & $0,525^{* *}$ \\
\hline Híbrido exp. normal vs Híbrido exp. alc ${ }^{+} / a l c$ & breaker & $-0,0037^{* *}$ & $4,765^{\mathrm{ns}}$ & $-0,110^{\mathrm{ns}}$ \\
\hline Híbrido exp. normal vs Híbrido exp. rin $^{+} /$rin & breaker & $0,0039^{* *}$ & $-14,085^{* *}$ & $0,240^{*}$ \\
\hline Híbrido exp. alc ${ }^{+} / a l c$ vs Híbrido exp. $\operatorname{rin}^{+} / r i n$ & breaker & $0,0075^{* *}$ & $-18,850^{* *}$ & $0,350^{* *}$ \\
\hline Carmen $F_{1}$ vs Híbrido experimental normal & intermediário & $0,0329^{* *}$ & $13,165^{* *}$ & $0,670^{* *}$ \\
\hline Carmen $F_{1}$ vs Híbrido experimental alc ${ }^{+} / a l c$ & intermediário & $0,0292^{* *}$ & $9,415^{*}$ & $0,880^{* *}$ \\
\hline Carmen $\mathrm{F}_{1}$ vs Híbrido experimental $\mathrm{rin}^{+} /$rin & intermediário & $0,0372^{* *}$ & $13,915^{* *}$ & $0,440^{* *}$ \\
\hline Híbrido exp. normal vs Híbrido exp. alc ${ }^{+} / a l c$ & intermediário & $-0,0037^{* *}$ & $-3,750^{\text {ns }}$ & $0,210^{*}$ \\
\hline Híbrido exp. normal vs Híbrido exp. rin $^{+} /$rin & intermediário & $0,0043^{* *}$ & $0,750^{\mathrm{ns}}$ & $-0,230^{*}$ \\
\hline Híbrido exp. alc ${ }^{+} / a l c$ vs Híbrido exp. $\operatorname{rin}^{+} / r i n$ & intermediário & $0,0080^{* *}$ & $4,500^{\mathrm{ns}}$ & $-0,440^{* * *}$ \\
\hline Carmen $F_{1}$ vs Híbrido experimental normal & maduro & $-0,0855^{* *}$ & $53,000^{* *}$ & $-0,005^{\mathrm{ns}}$ \\
\hline Carmen $\mathrm{F}_{1}$ vs Híbrido experimental alc ${ }^{+} / a l c$ & maduro & $-0,0221^{* *}$ & $75,990^{* *}$ & $0,180^{*}$ \\
\hline Carmen $\mathrm{F}_{1}$ vs Híbrido experimental $\mathrm{rin}^{+} /$rin & maduro & $0,0559^{* *}$ & $57,090^{* *}$ & $0,145^{\text {ns }}$ \\
\hline Híbrido exp. normal vs Híbrido exp. alc ${ }^{+} / a l c$ & maduro & $0,0634^{* *}$ & $22,990^{* *}$ & $0,185^{*}$ \\
\hline Híbrido exp. normal vs Híbrido exp. rin $^{+} /$rin & maduro & $0,1414^{*}$ & $4,090^{\mathrm{ns}}$ & $0,150^{\mathrm{ns}}$ \\
\hline Híbrido exp. alc ${ }^{+} / a l c$ vs Híbrido exp. $\operatorname{rin}^{+} / r i n$ & maduro & $0,0780^{* * *}$ & $-18,900^{* *}$ & $-0,035^{\mathrm{ns}}$ \\
\hline C.V. $(\%)$ & & 0,95 & 2,96 & 3,11 \\
\hline
\end{tabular}

**** Significativo ao nível de $1 \%$ e $5 \%$, respectivamente, pelo teste $\mathbf{F}$. 
Os alelos mutantes alc e rin em heterozigose não influenciaram a textura dos frutos em nenhum dos estádios de maturação, quando comparados ao genótipo normal (Tabela 3). Entretanto, nos estádios breaker e intermediário, as estimativas do contraste [Carmen $\mathrm{F}_{1}\left(\mathrm{rin}^{+} / \mathrm{rin}\right)$ vs Híbrido experimental $\left.\mathrm{rin}^{+} / \mathrm{rin}\right]$, para a textura, mostram que o background genético do híbrido Carmen $F_{1}$ leva à obtenção de frutos mais firmes, quando comparados ao background dos hí- bridos experimentais. O genótipo alc ${ }^{+} /$alc atuou no sentido de reduzir a atividade da enzima poligalacturonase dos frutos nos três estádios de maturação considerados. Constatou-se, também, redução na atividade da enzima pectinametilesterase no estádio maduro devido ao genótipo $a l c^{+} / a l c^{+}$. Com relação à enzima poligalacturonase, confirmou-se também o efeito do genótipo $\mathrm{rin}^{+} / \mathrm{rin}$ na redução da sua atividade.

TABELA 3 - Contrastes não ortogonais envolvendo 4 híbridos de tomateiro 'longa-vida' e suas estimativas para textura, poligalacturonase e pectinametilesterase em três estádios de maturação dos frutos. Lavras-MG: UFLA, 2001 .

\begin{tabular}{|c|c|c|c|c|}
\hline \multirow[b]{2}{*}{ Contrastes de Interesse } & \multirow{2}{*}{$\begin{array}{l}\text { Estádio de } \\
\text { maturação }\end{array}$} & \multicolumn{3}{|c|}{ Estimativa dos contrastes } \\
\hline & & $\begin{array}{c}\text { Textura } \\
\text { (N) }\end{array}$ & $\begin{array}{c}\text { PG } \\
\text { (UAE) }\end{array}$ & $\begin{array}{c}\text { PME } \\
\text { (UAE) }\end{array}$ \\
\hline Carmen $F_{1}$ vs Híbrido experimental normal & breaker & $4.538^{* *}$ & $-3.639^{* *}$ & $62.50^{\mathrm{ns}}$ \\
\hline Carmen $\mathrm{F}_{1}$ vs Híbrido experimental alc $/$ alc & breaker & $5.015^{* *}$ & $-1.074^{\mathrm{ns}}$ & $-62.50^{\mathrm{ns}}$ \\
\hline Carmen $\mathrm{F}_{1}$ vs Híbrido experimental $\mathrm{rin}^{+} / \mathrm{rin}$ & breaker & $3.543^{* *}$ & $0.065^{\mathrm{ns}}$ & $156.25^{\mathrm{ns}}$ \\
\hline Híbrido experimental normal vs Híbrido exp. alc $/ a l c$ & breaker & $0.477^{\mathrm{ns}}$ & $2.565^{*}$ & $-125.00^{\mathrm{ns}}$ \\
\hline Híbrido experimental normal vs Híbrido exp. $\mathrm{rin}^{+} / \mathrm{rin}$ & breaker & $-0.995^{\mathrm{ns}}$ & $3.704^{* *}$ & $93.75^{\mathrm{ns}}$ \\
\hline Híbrido experimental alc ${ }^{+} / a$ lc vs Híbrido exp. $\mathrm{rin}^{+} / \mathrm{rin}$ & breaker & $-1.473^{*}$ & $1.139^{\mathrm{ns}}$ & $218.75^{*}$ \\
\hline Carmen $F_{1}$ vs Híbrido experimental normal & intermediário & $2.363^{* *}$ & $-3.593^{* *}$ & $375.00^{* *}$ \\
\hline Carmen $\mathrm{F}_{1}$ vs Híbrido experimental alc $/$ alc & intermediário & $2.683^{* *}$ & $5.870^{* *}$ & $31.25^{\mathrm{ns}}$ \\
\hline Carmen $\mathrm{F}_{1}$ vs Híbrido experimental rin $^{+} /$rin & intermediário & $1.915^{* *}$ & $5.245^{* *}$ & $0.00^{\mathrm{ns}}$ \\
\hline Híbrido experimental normal vs Híbrido exp. alc ${ }^{+} / a l c$ & intermediário & $0.320^{\mathrm{ns}}$ & $9.463^{* *}$ & $-343.75^{* *}$ \\
\hline Híbrido experimental normal vs Híbrido exp. $\operatorname{rin}^{+} /$rin & intermediário & $-0.448^{\mathrm{ns}}$ & $8.838^{* *}$ & $-375.00^{* *}$ \\
\hline Híbrido experimental alc ${ }^{+} / a l c$ vs Híbrido exp. $\mathrm{rin}^{+} / \mathrm{rin}$ & intermediário & $-0.768^{\mathrm{ns}}$ & $0.625^{\mathrm{ns}}$ & $-31.25^{\mathrm{ns}}$ \\
\hline Carmen $\mathrm{F}_{1}$ vs Híbrido experimental normal & maduro & $0.930^{\mathrm{ns}}$ & $-2,009^{\mathrm{ns}}$ & $-2531.25^{* *}$ \\
\hline Carmen $\mathrm{F}_{1}$ vs Híbrido experimental alc ${ }^{+} / a l c$ & maduro & $0.393^{\mathrm{ns}}$ & $3.023^{*}$ & $781.25^{* *}$ \\
\hline Carmen $\mathrm{F}_{1}$ vs Híbrido experimental rin $^{+} /$rin & maduro & $0.815^{\mathrm{ns}}$ & $0.426^{\mathrm{ns}}$ & $1093.75^{* *}$ \\
\hline Híbrido experimental normal vs Híbrido exp. alc ${ }^{+} / a l c$ & maduro & $0.538^{\mathrm{ns}}$ & $5.032^{* *}$ & $3312.50^{* *}$ \\
\hline Híbrido experimental normal vs Híbrido exp. $\mathrm{rin}^{+} / \mathrm{rin}$ & maduro & $-0.115^{\mathrm{ns}}$ & $2.435^{\mathrm{ns}}$ & $3625.00^{* *}$ \\
\hline Híbrido experimental alc ${ }^{+} / a l c$ vs Híbrido exp. $\mathrm{rin}^{+} / \mathrm{rin}$ & maduro & $0.423^{\mathrm{ns}}$ & $-2.597^{*}$ & $312.50^{* *}$ \\
\hline C.V. $(\%)$ & & 12.41 & 6.84 & 3.07 \\
\hline
\end{tabular}

**** Significativo ao nível de $1 \%$ e $5 \%$, respectivamente, pelo teste $\mathbf{F}$. 
Em frutos maduros, o genótipo $\mathrm{rin}^{+} /$rin também foi responsável pela redução na atividade da pectinametilesterase. A atividade dessa enzima pode também ser função da ação de outros locos gênicos: as estimativas do contraste [Carmen $\mathrm{F}_{1}\left(\mathrm{rin}^{+} / \mathrm{rin}\right)$ vs Híbrido experimental $\mathrm{rin}^{+} / \mathrm{rin}$ ] indicaram que o background do híbrido comercial Carmen $\mathrm{F}_{1}$, quando comparado ao do híbrido experimental (Floradade x Tropic), foi responsável por maior atividade enzimática da poligalacturonase. no estádio intermediário. A característica de longo período de conservação em pós-colheita atribuída a Carmen $\mathrm{F}_{1}$ é, pois, função tanto do genótipo $\mathrm{rin}^{+} / \mathrm{rin}$ quanto de um background genético favorável.
A análise de contrastes não-ortogonais envolvendo os carboidratos da parede celular (Tabela 4) indica que para o estádio breaker não houve influência dos genes em heterozigose para as características celulose, hemicelulose e pectina. No estádio intermediário, o genótipo $\mathrm{rin}^{+} / \mathrm{rin}$ promoveu redução na fração hemicelulose, quando comparado com o seu isogênico normal. Pode-se inferir sobre algum efeito do background sobre essa característica, uma vez que o híbrido experimental heterozigoto no loco rin apresentou redução significativa na fração hemicelulose, quando comparado com o híbrido comercial Carmen $\mathrm{F}_{1}$, no estádio intermediário de maturação.

TABELA 4 - Contrastes não-ortogonais e suas estimativas para celulose, hemicelulose, pectina em três estádios de maturação de frutos de híbridos de tomateiro. Lavras-MG: UFLA, 2001.

\begin{tabular}{|c|c|c|c|c|}
\hline \multirow[b]{2}{*}{ Contrastes de Interesse } & \multirow{2}{*}{$\begin{array}{l}\text { Estádio de } \\
\text { maturação }\end{array}$} & \multicolumn{3}{|c|}{ Estimativa de contrastes } \\
\hline & & $\begin{array}{l}\text { Celulose } \\
\text { (\% mpc) }\end{array}$ & $\begin{array}{l}\text { Hemicelulose } \\
\text { (\% mpc) }\end{array}$ & $\begin{array}{l}\text { Pectina } \\
\text { (\% mpc) }\end{array}$ \\
\hline Carmen $F_{1}$ vs Híbrido experimental Normal & breaker & $-3.420^{\mathrm{ns}}$ & $1.520^{\mathrm{ns}}$ & $-1.885^{\mathrm{ns}}$ \\
\hline Carmen $\mathrm{F}_{1}$ vs Híbrido experimental alc ${ }^{+} / a l c$ & breaker & $-2.230^{\mathrm{ns}}$ & $1.375^{\mathrm{ns}}$ & $0.045^{\mathrm{ns}}$ \\
\hline Carmen $\mathrm{F}_{1}$ vs Híbrido experimental rin $^{+} / \mathrm{rin}$ & breaker & $-5.425^{\mathrm{ns}}$ & $0.840^{\mathrm{ns}}$ & $-1.175^{\mathrm{ns}}$ \\
\hline Híbrido exp. normal vs Híbrido exp. alc ${ }^{+} / a l c$ & breaker & $1.190^{\mathrm{ns}}$ & $-0.840^{\mathrm{ns}}$ & $1.930^{\mathrm{ns}}$ \\
\hline Híbrido exp. normal vs Híbrido exp. $\operatorname{rin}^{+} /$rin & breaker & $-2.005^{\mathrm{ns}}$ & $-0.680^{\mathrm{ns}}$ & $0.710^{\mathrm{ns}}$ \\
\hline Híbrido exp. alc/alc vs Híbrido exp. $\mathrm{rin}^{+} / \mathrm{rin}$ & breaker & $-3.195^{\mathrm{ns}}$ & $-0.535^{\mathrm{ns}}$ & $-1.220^{\mathrm{ns}}$ \\
\hline Carmen $F_{1}$ vs Híbrido experimental Normal & intermediário & $5.390^{\mathrm{ns}}$ & $1.320^{\mathrm{ns}}$ & $-0.725^{\mathrm{ns}}$ \\
\hline Carmen $\mathrm{F}_{1}$ vs Híbrido experimental alc ${ }^{+} / a l c$ & intermediário & $1.755^{\mathrm{ns}}$ & $3.505^{* *}$ & $-1.625^{\mathrm{ns}}$ \\
\hline Carmen $\mathrm{F}_{1}$ vs Híbrido experimental $\mathrm{rin}^{+} /$rin & intermediário & $-3.755^{\mathrm{ns}}$ & $4.410^{* *}$ & $-2.175^{\mathrm{ns}}$ \\
\hline Híbrido exp. normal vs Híbrido exp. alc ${ }^{+} / a l c$ & intermediário & $-3.635^{\mathrm{ns}}$ & $2.185^{\mathrm{ns}}$ & $-0.900^{\mathrm{ns}}$ \\
\hline Híbrido exp. normal vs Híbrido exp. $\operatorname{rin}^{+} /$rin & intermediário & $-9.145^{\mathrm{ns}}$ & $3.090^{*}$ & $-1.450^{\mathrm{ns}}$ \\
\hline Híbrido exp. alc ${ }^{+} / a l c$ vs Híbrido exp. $\operatorname{rin}^{+} / \mathrm{rin}$ & intermediário & $-5.510^{\mathrm{ns}}$ & $0.905^{\mathrm{ns}}$ & $-0.550^{\mathrm{ns}}$ \\
\hline Carmen $F_{1}$ vs Híbrido experimental Normal & maduro & $2.160^{\mathrm{ns}}$ & $0.305^{\mathrm{ns}}$ & $2.395^{\mathrm{ns}}$ \\
\hline Carmen $\mathrm{F}_{1}$ vs Híbrido experimental alc $/$ alc & maduro & $4.305^{\mathrm{ns}}$ & $1.265^{\mathrm{ns}}$ & $0.465^{\mathrm{ns}}$ \\
\hline Carmen $\mathrm{F}_{1}$ vs Híbrido experimental $\operatorname{rin}^{+} /$rin & maduro & $8.570^{*}$ & $1.925^{\mathrm{ns}}$ & $4.990^{* *}$ \\
\hline Híbrido exp. normal vs Híbrido exp. alc ${ }^{+} / a l c$ & maduro & $2.145^{\mathrm{ns}}$ & $0.960^{\mathrm{ns}}$ & $-1.930^{\mathrm{ns}}$ \\
\hline Híbrido exp. normal vs Híbrido exp. $\operatorname{rin}^{+} /$rin & maduro & $6.410^{*}$ & $1.620^{\mathrm{ns}}$ & $2.595^{*}$ \\
\hline Híbrido exp. alc ${ }^{+} / a l c$ vs Híbrido exp. $\operatorname{rin}^{+} / \mathrm{rin}$ & maduro & $4.265^{\mathrm{ns}}$ & $0.660^{\mathrm{ns}}$ & $4.525^{* *}$ \\
\hline C.V. $(\%)$ & & 9.81 & 9.87 & 8.86 \\
\hline
\end{tabular}

**, Significativo ao nível de $1 \%$ e $5 \%$, respectivamente, pelo teste $\mathrm{F}$. 
No estádio maduro, o genótipo $\mathrm{rin}^{+} /$rin promoveu redução significativa nos teores de celulose e pectina do material da parede celular, quando comparado ao genótipo normal; verificou-se também efeito do background sobre essas duas características, uma vez que as estimativas dos contrastes [Carmen $\mathrm{F}_{1}\left(\mathrm{rin}^{+} / \mathrm{rin}\right)$ vs Híbrido experimental $\mathrm{rin}^{+} / \mathrm{rin}$ ] foram positivas e significativas. Isso é indicativo de que o background híbrido experimental TOM-610 x Floradade é favorável à obtenção de frutos maduros com menor teor de celulose e pectina, quando comparado com o background do híbrido Carmen $\mathrm{F}_{1}$, o que sugere a ocorrência no primeiro de uma maior perda e possível desestruturação de parede celular, muito embora a redução nos níveis dessas variáveis não tenha resultado em significativa redução na textura dos frutos no estádio maduro. Para a fração pectina, o uso do loco $\mathrm{rin}^{+} / \mathrm{rin}$ mostrou-se desfavorável quando comparado ao loco alc $/$ alc, conforme pode ser constatado pela estimativa do contraste (Híbrido experimental alc ${ }^{+} /$alc vs Híbrido experimental $\mathrm{rin}^{+} / \mathrm{rin}$ ). No estádio maduro, o híbrido experimental de genótipo $\mathrm{rin}^{+} /$rin apresentou menores níveis de celulose e pectina na parede celular, não influenciando o componente hemicelulose. Com esse comportamento, infere-se que o alelo $\mathrm{rin}^{+} / \mathrm{rin}$ favoreceu maior despolimerização e solubilização de parede celular, o que levou a uma perda líquida dos componentes celulose e pectina. Essa perda possivelmente está associada a maior atividade de enzimas hidrolases e liases de parede celular. Entretanto, nesse caso, o nível de perda dos componentes de parede celular não influenciou o fator textura de frutos maduros, pois não se verificou diferença significativa entre genótipos nessas condições.

\section{CONCLUSÕES}

Nenhum dos efeitos desfavoráveis de alc ${ }^{+} /$alc ou $\mathrm{rin}^{+} /$rin foram de magnitude suficientemente grande de modo a impedir a utilização desses alelos no melhoramento, uma vez que esses efeitos podem ser compensados pelo background genético utilizado. Ambos os mutantes ( $r i n$ e $a l c$ ) têm potencial para serem usados, em heterozigose, no desenvolvimento de cultivares de tomate, com melhor conservação de frutos em póscolheita.

\section{REFERÊNCIAS BIBLIOGRÁFICAS}

ARAÚJO, M. L. Interações intra-loco e inter-locos alcobaça, crimsom e high pigment sobre características de qualidade e de produção de frutos do tomateiro. 1997. 131 p. Tese (Doutorado em Fitotecnia) - Universidade Federal de Lavras, Lavras, 1997.

ASSOCIATION OF OFFICIAL AGRICULTURAL CHEMISTS. Official methods of analysis of the Association of official analytical chemistry. 11. ed. Washington, $1992.1115 \mathrm{p}$.

BITTER, T.; MUIR, H. M. A modified uronic acid carbazole reaction. Analytical Biochemistry, New York, v. 34, p. 330-334, 1962.

BRUINSMA, J. The quantitative analysis of chlorophylls A and B in plant extracts. Photochemistry and Photobiology, Elmsford, v. 2, p. 241-249, 1963.

DISCHE, E. Color reactions of carbohydrates. In: WHISTLER, R. L.; WOLFRAM, M. L. (Eds.). Methods in Carbohydrates chemistry. New York: Academic, 1962. v. 1, p. 477-512.

FILGUEIRAS, H. A. C. Bioquímica da maturação de tomates híbridos heterozigotos no loco 'alcobaça'. 1996. 118 f. Tese (Doutorado em Ciências dos Alimentos) - Universidade Federal de Lavras, 1996.

GÓMEZ, R.; VARÓN, R.; AMO, M.; TARDÁGUILA, J.; PARDO, J. E. Differences in the rate of coloration in tomato fruit. Journal of Food Quality, Connecticut, v. 21, n. 4, p. 329-339, July 1998.

INSTITUTO ADOLFO LUTZ. Normas analíticas, métodos químicos e físicos para análise de alimentos. 3. ed. São Paulo, 1985. v. 1, 533 p.

KOPELIOVITCH, E.; RABINOWITCH, H. D.; MIZRAHI, Y.; KEDAR, N. The potencial of ripening mutants for extending the storage life of the tomato fruit. Euphytica, Wageningen, v. 28, n. 1, p. 99-104, Feb. 1979.

LOBO, M. Genetic and physiological studies of the "Alcobaça" tomato ripening mutant. 1981. 107 p. Thesis (Ph.D. genetic an plant development) - University of Florid, Florid, 1981.

LURIE, S.; HANDROS, A.; FALLIK, E.; SHAPIRA, R. Reversible inhibition of tomato fruit gene expression at high temperature. Effects on tomato fruit ripening. Plant Physiology, Washington, v. 110, n. 4, p. 12071214, Apr. 1996. 
MITCHAM, E. J.; McDONALD, R. E. Cell wall modification during ripening of 'Keit' and 'Tommy Atkins' mango fruit. Journal of the American Society for Horticultural Science, Alexandria, v. 17, n. 6, p. 919-924, Nov. 1992.

NAGATA, M.; YAMASHITA, I. Simple method for simultaneous determination of chlorophyll and carotenoids in tomato fruit. Nippon Shokuhin Kogyo Gakkaishi, Tokio, v. 39, n. 10, p. 925-928, 1992.

TIGCHELAAR， E. C.; MCGLASSON， W. B.; BUESCHER, R. W. Genetic regulation of tomate fruit ripening. HortScience, Alexandria, v. 13, n. 5, p. 508513, Oct. 1978.

VILAS BOAS, E. V. de B. Maturação pós-colheita de híbridos de tomate heterozigotos no loco alcobaça. 1998. 105 p. Tese (Doutorado em Ciências dos Alimentos) - Universidade Federal de Lavras, Lavras, 1998.

YOUNG, T. E.; JUVIK, J. A.; SULLIVAN, J. G. Accumulation of the components of total solids in ripening fruits of tomato. Journal of the American Society for Horticultural Science, Mout, v. 118, n. 2, p. 286292, Mar. 1993. 